\title{
Blockchain Technology in Agriculture Value Chains: Prospects and Impediments
}

\author{
Jason $\mathbf{W}^{*}$ \\ University of Queensland, Australia
}

Submission: October 30, 2017; Published: November 15, 2017

*Corresponding author: Jason W, University of Queensland, School of Agriculture and Food Science, Australia, Email: jason.west@uq.edu.au

\section{Opinion}

Block chains are now firmly established as a digital technology that combines cryptographic, data management, networking, and incentive mechanisms to support the verification, execution, and recording of transactions between parties. While block chain technologies were originally intended to support new forms of digital currency for easier and secure payments, they now hold great promise as a new foundation for all forms of transactions. Agribusiness stands to become a key beneficiary of this technology as a platform to execute 'smart contracts' for transactions, particularly for high-value produce.

\section{Distributed Ledgers}

First it is important to distinguish between private digital currencies and the distributed ledger and block chain technologies that underlie them. The distributed and crossborder nature of digital currencies like Bit coin means that regulation of the core protocols of these systems by central banks is unlikely to be effective. Monetary authorities are focused more on understanding 'on-ramps' and 'off-ramps' that constitute the links to the traditional payments system rather than being able to monitor and regulate the currency itself. In contrast to the digital currency feature of block chain, the distributed ledger feature has the potential for widespread use in agribusiness and trade financing, especially where workflows involve many different parties with no trusted central entity.

\section{Smart Contracts}

Block chains have substantial potential to disintermediate existing third-party arrangements. In economies where thirdparty supply chain participants are not fully trustworthy, block chain systems can provide immutable and non-repudiated assurance of the source of a product. In economies where thirdparty actors are more trustworthy, the benefits of block chains are embedded in the cost reduction of establishing business relationships as well as mitigation of risk in the transactions themselves. Since supply chains are so critical for agribusiness to move goods across organisational boundaries, contracts that support the supply chain are necessarily complex and dynamic, and usually involve multiple parties all facing their own regulatory and logistic constraints.

Payments are contingent on information content and quality at many different points, which highlights that information exchange in a supply chain, is just as important as the physical exchange of the goods themselves. Thorough documentation and evidence of provenance can thus expedite the processing of supply through bottlenecks such as at customs and biosecurity. This leads to obvious benefits, particularly when trade finance is a primary vehicle through which cross-border transactions occur.The neutral ground provided by the block chain ledger allows complex agribusiness operations to integrate the disparate participants in their supply chain, as well as maintain an audit trail to govern and promote transparency through an entire suite of activities.

\section{Provenance}

Customers are increasing their demand for knowledge not only on where food ingredients were grown but also on how products were processed and then distributed. This is becoming important in establishing confidence around food safety, particularly for high-quality brands. The need to prevent fraud in food supply chains to guarantee the provenance of produce is critical for the protection of high-value goods. Producers and supply chain actors are beginning to actively bear the costs of operating block chain infrastructure to establish provenance as a key feature of the brand. Distributed ledgers ensures that information about goods and supply chain events cannot be falsified or created without proper authority.

The block chain promotes a collaborative process using smart contracts which can be generated automatically from a form of process model. Smart contracts can enforce a process so that messages arriving at the wrong point in the process can 
be rejected, messages are only accepted from authorised supply chain participants(e.g., biosecurity clearance can only be granted by the a biosecurity participant) and various conditions can be specified through the process and executed in the smart contract directly. This allows payments to be made when contractual conditions are met.

\section{Impediments}

The block chain does not come without its challenges. First cross-border payments can be complicated and made more expensive by the difficulties of satisfying anti-money laundering and counter-terrorism financing regulations. These transactions can have high latency, with transaction times being as high as 5 days when transacting with high-risk countries. Second, block chain currencies such as Bitcoin and Ethereum cannot match the typical transaction volume of conventional systems. This is being addressed using new mechanisms (e.g., sharding, state channels, and reduced inter-block time) but continual development will be needed.

Finally, smart contracts may have some resistance in being regarded at law as legal contracts. In the context of block chains, smart contracts resemble the source code text of a program or a distributed process executing a digital version of that program. In this sense a smart contract is fundamentally not an agreement. However smart contracts may be used as evidence of an agreement or, alternatively the means for the execution of the provisions of a contract. Nevertheless some legal impediments to block chains as smart contracts may limit their popularity.

\section{Research Prospects}

The block chain has great potential to act as a single, immutable record of a food's journey from its source to the consumer. Encryption and signature of provenance data makes it impossible to alter. Suppliers can see exactly where their food came from and how long it took to get there. They can also trace damaged or missing produce back to its precise location; the entire route can be tracked along the block chain. This has added benefits of not only guaranteeing provenance of highquality produce like seafood but also detecting inefficiencies in food distribution. Block chain is one of the most promising technologies now available to the agricultural sector. The development of this field offers an exciting area for future research for improving food quality and independent certification, supply chain efficiency, cross-border flows of produce and trade finance.

\section{Your next submission with Juniper Publishers will reach you the below assets}

- Quality Editorial service

- Swift Peer Review

- Reprints availability

- E-prints Service

- Manuscript Podcast for convenient understanding

- Global attainment for your research

- Manuscript accessibility in different formats

( Pdf, E-pub, Full Text, Audio)

- Unceasing customer service

Track the below URL for one-step submission https://juniperpublishers.com/online-submission.php 